\title{
Futsal World Cup: Differences Created by Winning, Losing and Drawing Variables in Scored Goals and Offensive Variations
}

\author{
Melih Balyan ${ }^{1}$, Faik Vural ${ }^{1}$ \\ ${ }^{1}$ Faculty of Sport Sciences, Ege University, İzmir, Turkey \\ Correspondence: Melih Balyan, Faculty of Sport Sciences, Ege University, 35040, İzmir, Turkey.
}

Received: February 25, 2018

Accepted: March 23, 2018

Online Published: March 29, 2018

doi:10.11114/jets.v6i5.3147

URL: https://doi.org/10.11114/jets.v6i5.3147

\begin{abstract}
Futsal, which can be defined as a new sports branch compared to football, has some shortcomings in comparison with football as well according to the studies carried out. Studies have rather focused on the movement characteristics of futsal players during the game and the physiological effects of games. On the other hand, there are only a limited number of studies conducted on game analysis. Therefore, as the primary goal of the present study, offensive variations that ended up as goals in all matches played in Futsal World Cup were analyzed. As the secondary goal, these parameters were studied in terms of the teams' winning-drawing-losing states during games. In the present study, a total of 52 matches of the teams playing in 2016 FIFA Futsal World Championship were analyzed. The analyses of the games were performed using the hand notation method. Differences between offensive variations (Diagonal, parallel, central and transition game forms, set games etc.) and the goals scored (shots taken, shots at goal, the area where the goals were scored, the way the goals were scored, the area where the foot hit the ball, block shoots etc.) were determined with One-way Anova and Kruskal-Wallis tests on SPSS version 20 in terms of 3 variables (win-loss-draw). The findings show that the winning teams had significantly more shots than the losing teams $(10.80,95 \% \mathrm{CI}$ (from 3,73 to 17,87 ) and that the number of shots at goal was also higher $(5.82,95 \% \mathrm{CI}$ (from 2, 43 to 9, 91) in terms of the teams' winning-losing-drawing states. However, no statistically significant difference was found between the areas where the shots were taken and the points they ended up at the goal. As for position specific games, on the other hand, statistically significant differences were found in terms of winning, losing and drawing states during the game $\left(\right.$ central $=\chi^{2}(2)=$ $10.500, p=.005$, diagonal $=\chi^{2}(2)=17.142, p=.000$, parallel $=\chi^{2}(2)=10.931, p=.004$, transition $=\chi^{2}(2)=28,587 p$ $=.000$ ). No statistically significant difference was found between set games ending up with goals and the teams' game score variables. The results obtained concerning offensive variations in a superior futsal championship reveal that positional games of dynamic style could be much more effective compared to set games of static starting positions in winning the game. Moreover, producing shooting positions and their accuracy levels seem to be an important factor affecting success. According to these results, it can be recommended that the trainings to be held should be designed to improve positional games that these should be planned as practices that result in shots.
\end{abstract}

Keywords: futsal, world cup, analysis, goals

\section{Introduction}

Due to the dynamism within the game of football, which can be played in different ways and under different conditions all over the world, the interest in football is gradually increasing. Within this development and growth, the organization and increased popularity of football and similar games around the world have been inevitable (Balyan, Vural \& Katipoğlu, 2016). FIFA, the association that forms the structure of this huge organization and helps its reshaping, has been looking for different organizations in order to increase the interest in football and the number of participants and audience. Women's football, beach football and futsal have a particular importance within this body (FIFA, 2016).

Futsal requires a good level of physical, technical and tactical performance since intermittent and high intensity activities are maintained continuously in an area of $40 \times 20$ meters and during a game duration of $2 \times 20$ minutes (the clock stops when the ball goes out of play). In addition, different game rules such as $6 \mathrm{~m}, 10 \mathrm{~m}$ penalty kicks and unlimited substitutions help futsal be played in a far more dynamic structure. Also, the fact that the viewers can watch all the activities in the game from a much closer point to the pitch compared to football has made the audience potential of futsal grow gradually in national and international (countries and clubs) official organizations since the 1930s (Ocak 
\& Buğdayc1, 2011; FIFA, 2012; Burns, 2004; Hermans \& Engler, 2010; The FA, 2005; Göktepe, 2014).

As a result of this increasingly growing interest in futsal, a necessity has come up to improve the characteristics of the branch. In this respect, different game structures have been specified such as the branch-specific game systems (1-2-1, 2-2, 4-0 etc.), its characteristics towards offence (fast-paced game, counter attack, game setting etc.) and defense (pressure at high intensity, pressure at the $3 / 4$ field, close defense etc.) As a result of its tactical development (Martic, 2016). Differences in the systems of the game have changed the technical and tactical requirements of the futsal branch and bought about a need for branch-appropriate player profiles. Analysis studies provide significant feedback in the determination of the effects created by the changes and branch-oriented player requirements.

In this respect, besides determining futsal players' physical characteristics, their technical, tactical and management-related (FIFA,2012; Barbero, Soto, Barbero \& Granda, 2008; Dogramaci, Watsford \& Murphy, 2011;Lapresa, Alvarez, Arana, Garzon \& Caballero, 2013; Bueno, Caetano, Souza, Moreira, Nakamura, Cunha, Moura, 2014; Costa, Gargonta, Greco, Mesquito, Silva, Müller \& Seabra, 2010; Castagna, D’Ottavio, Vera \& Alvarez, 2009; Leite, 2012; Moura, 2011; Alvarez, D’Ottavio, Vera \& Castagna, 2009; Castagna \& Alvarez, 2010; Ayala, Baranda, Croix \& Santonja, 2012; Vilar, 2014; Dos Santos \& Navarro, 2010; Alvurdu, 2013; Göral \& Saygin, 2011) characteristics were also examined broadly through the analysis studies carried out. However, a majority of these studies have focused on the physiological requirements of futsal and it is seen that the number of studies on technical and tactical analysis is only limited. Yet, through correct analyses to be carried out, positive qualities of athletes could be further improved and new working systems could be developed for their negative qualities by determining the activity areas of successful teams and desired improvements can be achieved through imitating successful teams (Bangsbo \& Peitersen, 2000). For all these reasons; the main purpose of the present study was to examine goal-bound offensive variations and the goals scored in all matches played in Futsal World Cup and the secondary purpose was to analyze these parameters in terms of the teams' winning-losing-drawing states within the game.

\section{Method}

\subsection{Study Group}

In the present study, a total of 52 matches played by the teams competing in 2016 FIFA Futsal World Championship were analyzed (an evaluation of 104 games as winners-losers-drawers). The tournament was participated by 7 European (Italy, Portugal, Spain, Russia, Azerbaijan, Ukraine, Kazakhstan), 5 Asian (Australia, Thailand, Iran, Uzbekistan, Vietnam), 4 South American (Brasil, Argentina, Columbia, Paraguay), 4 North American (Costa Rica, Cuba, Guatemala, Panama), 3 African (Egypt, Tunisia, Mozambique) and 1 Oceania (Solomon Islands) countries.

\subsection{Data Collection}

The analysis of the activities pertaining to the offensive variations during the games was performed using hand notation (marking method) method. Differences between offensive variations (Diagonal, parallel, central and transition game forms, set games etc.) and the goals scored (shots taken, shots at goal, the area where the goals were scored, the way the goals were scored, the area where the foot hit the ball, block shoots etc.) were examined in terms of 3 different variables (win-loss-draw). Moreover, goals scored were also analyzed in terms of the areas they were taken from and their end points at the goal (Figure 1).

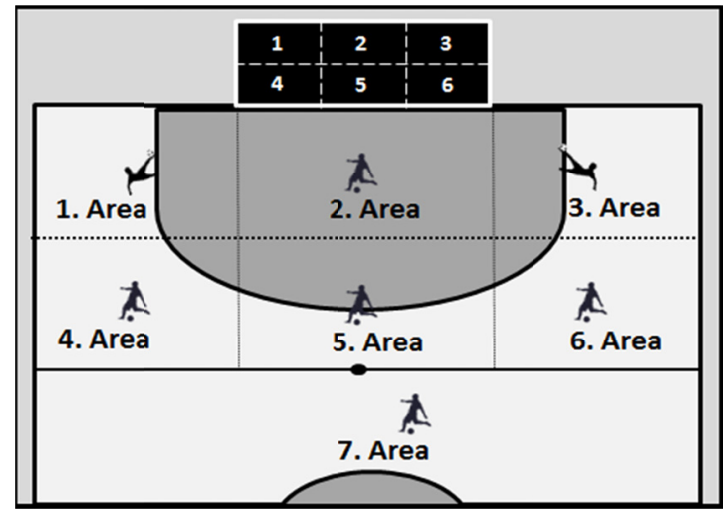

Figure 1. The areas where the goals were taken from and their end points at the goal

Offensive Variations:

Transitions: Passing from defensive position to offensive position in a very short time in order to achieve the most accurate and effective offense in a short time. The aim is to catch the opponent off guard and end the attack. 
Pivot game: Coming of the player at the position of pivot center-forward to catch the ball from the center (mix pivot) or as the mobile pivot (approaching to borders).

Set plays: Offensive variations taken from set play positions in the form of free kicks, throw-ins, corner kicks, center kicks and throw-outs.

Positional game: Offensive variations that include assisted or non-assisted passes taken in order to make space in the opponent's area and to take the ball to this space.

Parallel game: Movement runs by the playmaker positioned in the center of the field after he/she makes a pass at the winger towards the front of the point where the pass was taken from. The aim of these runs is to take the ball from a closer point to the opponent's goal and to help develop the attack.

Diagonal game: Movement runs by the central playmaker after he/she makes a pass at the winger in cross direction of the point where the pass was taken from. The aim of these runs is to take the ball from a closer point to the opponent's goal and to help develop the attack (9).

6 meter penalty kick: The direct free kick gained by commitment of 10 offences specified by FIFA within the penalty area.

10 meter kick: Direct free kicks taken to the goal from a 10 distance for each foul committed by the opponent after they use 5 fouls in one half.

\subsection{Data Analysis}

Means \pm standard deviations were determined according to the dependent variables of winning, losing and drawing. Assumption of normality was confirmed with Shapiro-Wilk and Kolmogorov-Simirnov tests $(\mathrm{p}>.05)$. In not normally distributed variables, nonparametric Kruskal-Wallis $\mathrm{H}$ test and Mann-Whitney $\mathrm{U}$ test were employed to find the differences between groups (winners, losers, drawers). Normally distributed data were analyzed using one-way ANOVA test. Effect size (eta squared, $\eta^{2}$ ) was used with values of $>.06$ and $>.15$ considered as moderate and large, respectively. Where significant main effects/interactions were detected, post-hoc analysis was performed using Tukey's HSD procedure. Statistical analyses were conducted using SPSS computer software (Version 20.0, SPSS Inc., Illinois, USA).

\section{Results}

36-group, 8-last 16 and 8-final games played during the championship were analyzed. Group matches ended in 32 wins, 32 losses (88\%), 4 draws (16\%), last 16 games ended in 6 wins, 6 losses (75\%), 2 draws (25\%) and final games ended in 7 wins, 7 losses $(87,5 \%), 1$ draw $(12,5 \%)$.

The examination of the shots taken showed that a total of 4500 shots were taken, $1615(35,8 \%)$, of which were shots on goal, $1419(31,53 \%)$ were missing and $1460(32,4 \%)$ of them ended in blocks. The assessments concerning the differences caused by winning, losing and drawing on shot variables are presented in Table 1.

Table 1. Results of the one-way ANOVA analysis concerning differences in shot variables according to game scores

\begin{tabular}{|c|c|c|c|c|c|c|c|}
\hline Variables & Score & $\mathbf{N}$ & $\mathbf{X}$ & SS & $\mathbf{F}$ & $\mathbf{p}$ & Significant Difference \\
\hline \multirow{3}{*}{ Number of Shots } & Win & 47 & 15.787 & 5.853 & \multirow{3}{*}{4.111} & \multirow{3}{*}{.019} & \multirow{3}{*}{$\begin{array}{l}\text { Win-Loss } \\
\text { Win-Draw }\end{array}$} \\
\hline & Loss & 47 & 13.021 & 6.472 & & & \\
\hline & Draw & 10 & 10.600 & 5.891 & & & \\
\hline \multirow{3}{*}{ Shots on Goal } & Win & 47 & 18.681 & 8.081 & \multirow{3}{*}{8.943} & \multirow{3}{*}{.001} & \multirow{3}{*}{ Win-Loss } \\
\hline & Loss & 47 & 12.851 & 5.594 & & & \\
\hline & Draw & 10 & 13.300 & 6.464 & & & \\
\hline \multirow{3}{*}{ Missing Shots } & Win & 47 & 14.766 & 6.062 & \multirow{3}{*}{2.333} & \multirow{3}{*}{.102} & \multirow{3}{*}{-} \\
\hline & Loss & 47 & 12.446 & 4.553 & & & \\
\hline & Draw & 10 & 14.000 & 3.681 & & & \\
\hline \multirow{3}{*}{ Shots ending in Blocks } & Win & 47 & 15.787 & 5.853 & \multirow[b]{2}{*}{4.111} & \multirow[b]{2}{*}{.019} & \multirow{3}{*}{ Win-Draw } \\
\hline & Loss & 47 & 13.021 & 6.472 & & & \\
\hline & Draw & 10 & & & & & \\
\hline
\end{tabular}

Kruskal-Wallis $\mathrm{H}$ test results showed that there were significant differences between GoalMinute1 $\left(\mathrm{x}^{2}(2)=13.674\right.$, $\mathrm{p}=.001)$, GoalMinute2 $\left(\mathrm{x}^{2}(2)=24.618, \mathrm{p}=.000\right)$, GoalMinute3 $\left(\chi^{2}(2)=19.137, \mathrm{p}=.000\right)$, GoalMinute4 $\left(\chi^{2}(2)=15.775\right.$, $\mathrm{p}=.000$ ) while no significant difference was found with GoalMinute5 according to game scores. In order to determine which group caused the difference, paired comparisons were performed in accordance with the Dunn's procedure. Bonferroni corrections were made for multiple comparisons and the statistical level of significance was accepted as $p$ $<.016$. The results of Post-hoc analysis showed that there were statistically significant differences between the winner (mean rank= 63.32) and loser (mean rank= 43.04) for GoalMinutel $(\mathrm{p}=.001)$; between the winner (mean rank $=67.56)$ loser (mean rank $=41.12)$ and winner-draw (mean rank $=35.20)$ for $(\mathrm{p}=.003)$ GoalMinute2; between the winner (mean 
rank $=65.65)$ and loser $($ mean rank $=41.65)$ for GoalMinute $3(\mathrm{p}=.000)$; and between the winner (mean rank $=64.26)$ and loser (mean rank $=41.44)$ for GoalMinute4 $(\mathrm{p}=.000)$.

Graph 1 shows the offensive variations after which the goals were scored, the differences they have in terms of game scores and their ratios to the total goals scored.

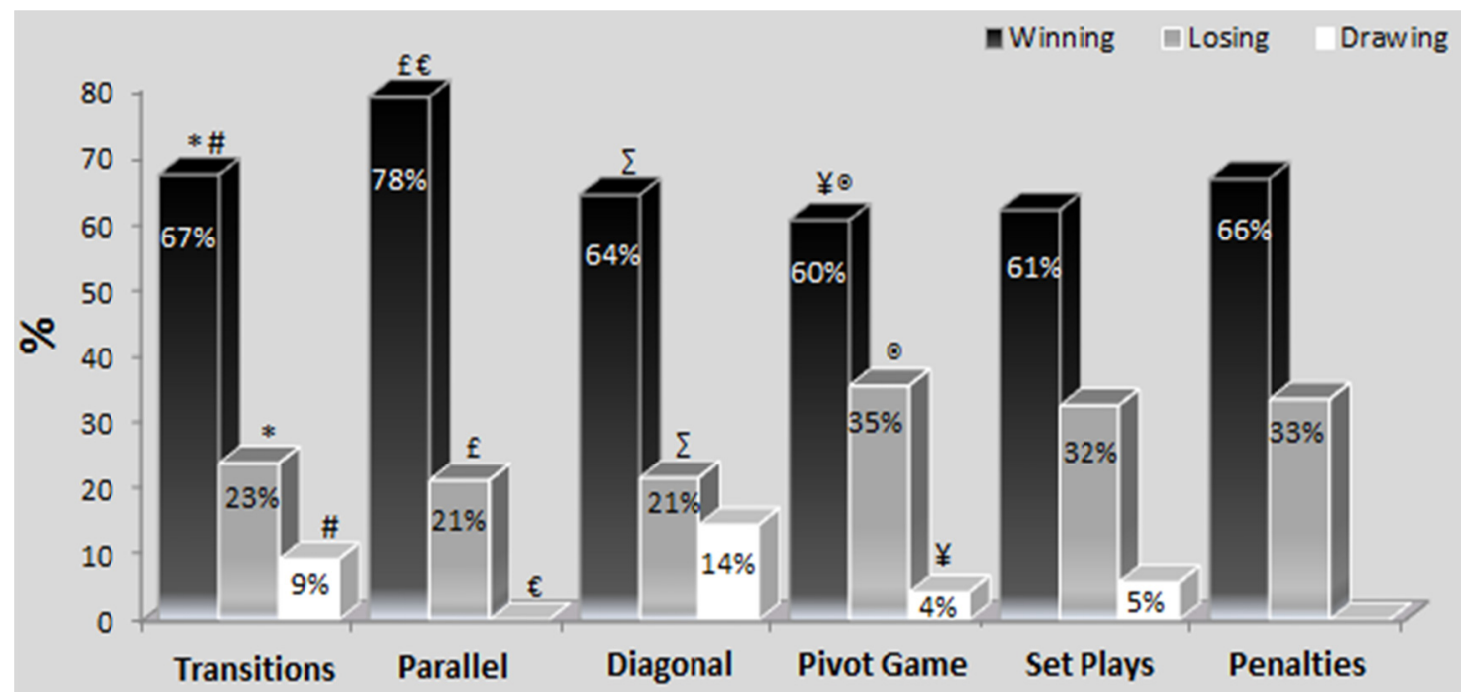

Graph 1 . The ratio of offensive scores that ended in goals to the total goals scored in similar variations in the tournament $(\%)\left({ }^{* \# \notin \in \sum ¥ \odot} \mathrm{p}<.016\right)$

The effectiveness levels of shots in terms of zones and their level of being on goal in terms of the spot where the shots ended in the goal and the effectiveness of ending in the goal of the goals scored in terms of zones are given in Figure 1. When the data concerning the areas where shots on the goal were taken and the foot these shots were taken with as well as the kicking technique used are examined; statistically significant differences were found between the winner (mean rank= 57.94) and loser (mean rank= 44.60) $(\mathrm{p}=.003)$ and between the loser and draw (mean rank=64.10) $(\mathrm{p}=.014)$, for VTBAinsideright1 $\left(\chi^{2}(2)=24.618, p=.001\right)$; between the winner (mean rank= 61.89) and loser (mean rank= 44.06) for VTBAinsideleft $2\left(\chi^{2}(2)=18.746, p=.000\right)$; between the winner $($ mean rank= 58.09) and loser $($ mean rank= 47.00) $(p=.003)$ for VTBAinsideleft5 $\left(\chi^{2}(2)=11.168, \mathrm{p}=.004\right)$, between the winner (mean rank= 59.71) and loser (mean rank= 46.10) $(\mathrm{p}=.014)$ for VTBAupright5 $\left(\chi^{2}(2)=8.354, \mathrm{p}=.015\right)$; between the winner (mean rank= 58.69) and loser (mean rank= 47.59) $(\mathrm{p}=.004)$ for VTBAup right6 $\left(\chi^{2}(2)=11.806, \mathrm{p}=.003\right)$. However, no statistically significant difference was found between the other variables concerning the shot characteristics.

In the number of ball contacts by the players before the goal (BCBG); statistically significant differences were found in the goals scored after 1 contact with the ball $\left(B C B G 1=\chi^{2}(2)=29.979 p=.000\right.$, between the winner and draw mean rank $=69.83-32.00 \mathrm{p}=.001$ and the winner and loser mean rank=39.53 $\mathrm{p}=.000)$ and 2 contacts with the ball $(\mathrm{BCBG} 2=$ $\chi^{2}(2)=23.714 \mathrm{p}=.000$, between the winner and draw mean $\mathrm{rank}=66.65-38.60 \mathrm{p}=.008$ and the winner and loser mean rank $=41.31 \mathrm{p}=.000$ ). No significant difference was observed in the numbers of other ball contacts in terms of game scores.

The effectiveness levels of shots in terms of zones and their ending points in the goal, the effectiveness of the shots on goal in terms of zones and the shots' levels of being in the goal in terms of their ending points in the goal are given in Figure 1.

It was found that the winning teams used the $4^{\text {th }}$ point $\left(\chi^{2}(2)=13.578 \mathrm{p}=.001\right)$ and the $6^{\text {th }}$ point $\left(\chi^{2}(2)=9.009 \mathrm{p}=.011\right)$ of the goal from Zone $1,5^{\text {th }}$ point $\left(\chi^{2}(2)=13.633 \mathrm{p}=.001\right)$ from Zone $2,4^{\text {th }}$ point $\left(\chi^{2}(2)=12.611 \mathrm{p}=.002\right)$ from Zone 5 , and $4^{\text {th }}$ point $\left(\chi^{2}(2)=9.009 \mathrm{p}=.011\right)$ and $5^{\text {th }}$ point $\left(\chi^{2}(2)=12.286 \mathrm{p}=.002\right)$ from Zone 6 significantly more effectively in comparison with the losing and drawing teams. 


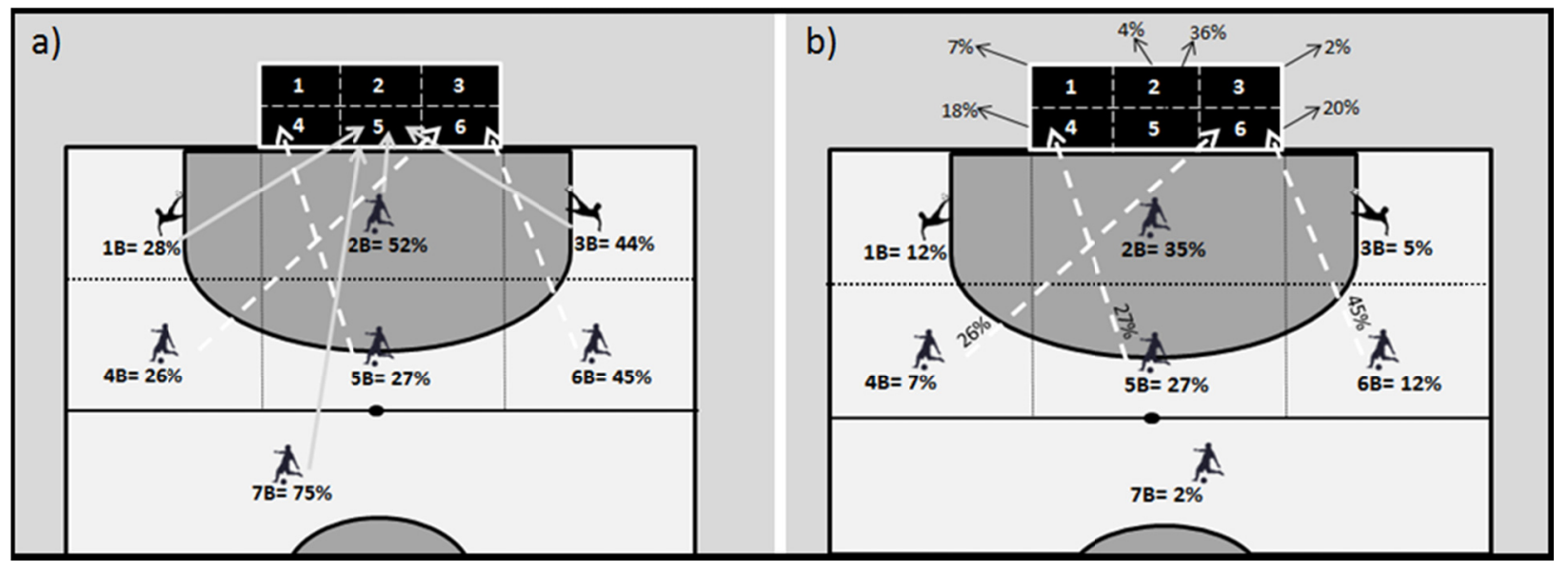

Figure 2. a) Effectiveness levels of the goals in terms of zones and their ending points in the goal, b) Ratios of shots on goal in terms of zones and the shots' being in the goal in terms of their ending points in the goal. (Z1: First zone, Z2:

Second zone, Z3: Third zone, Z4: Fourth zone, Z5: Fifth zone, Z6: Sixth zone, Z7: Seventh zone)

\section{Discussion and Conclusion}

Studies on the analysis of offensive variations and the positions ending in goal in Futsal have been previously carried out in different ways. These studies have mainly been conducted as an overall analysis of positions that ended in goals and general information was given in accordance with these ratios. In the study carried out by Doğramac1 (2011), it was revealed that mobility within the game increased parallel with the increase in league quality (Dogramac1 et al, 2011), the examination of 3 games of Portugal National team in 2012 showed the importance of set games (Leite, 2012), the study of 9 games played in the World Cup in 2008 highlighted the effectiveness of fast offenses (Dos Santos et al 2010) and the analysis of the 2012 World Cup emphasized the importance of shot accuracy ratios (Göral \& Saygin, 2011). However, the biggest shortcoming of these studies $s$ that they ignored the fact that scores during the match could influence the teams' playing styles and tactical variations. Failing to evaluate the analyses according to the teams' scores may cause teams and trainers to design their practices incompetently from time to time. In our study, however, positions that ended in goals were examined according to scores and the positive qualities of the winning teams were tried to be evaluated for the conditions of that time.

The main finding obtained from the present study is that winning teams could perform offensive tactical variations better in comparison with the losers and drawers. This finding reveals that futsal has now started to reflect its own structural qualities which are different from football. Particularly winning teams are seen to use parallel, diagonal and central games more effectively in transitions from defense to offense tactically. In a superior futsal championship, these results obtained concerning offensive variations show that positional games of dynamic style may be much more effective than the static starting position set games in winning a game. In other studies, although offensive variations were not analyzed as specific parameters like in our study, the findings that the most number of goals were scored following organized attacks supports our study. In these studies, the ratio of the goals scored from organized attacks to the total number of goals was $65.38 \%$ for Brazil in the U-20 World Cup held in Egypt in 2003 (Silva et al,2004) and it was $56.89 \%$ for Portugal in the 2010 European Cup (Leite, 2012). As a result of these findings, it can be envisaged that if teams include more transition positions and position practices (parallel, diagonal, central etc.) that can be arranged with assisted/non-assisted passes in their pre-game practices, it could contribute significantly to winning the game. In addition to these practices, while planning trainings, it would be much more effective to consider that, in passes in organized attacks, pass distances do not usually exceed 10 meters, stop-passes are generally used, diagonal passes are the most commonly preferred pass directions, the central area is used most for organized attacks as the game area (Ren, 2013) and that defense players positioned at different distances are used (Travassos,Duarte,Vilar,Davids, \& Araújo, 2012). Moreover, using video analyses of the studies carried out could make important contributions to the development of futsal-specific techniques (Travassos,Araújo,Davids, Esteves \& Fernandes,2012). The importance of such practices has also been highlighted in the reports recently developed by FIFA $(2012,2016)$ and it has been presented as a significant quality of successful teams.

In the present study, which examined the 2016 World Cup, it was found that 79 goals were scored in total in the static start set games while this number was given as 43 in the study conducted by Leite analyzing Portugal among the 2010 European Cup finalists and it was determined as 59 goals in the 2012 World Cup (FIFA, 2012; Leite, 2012; FIFA, 2016). 
Despite the increase in the number of goals, in our study, no significant difference was found between winning, losing and drawing in the goals scored with set games that start from static positions. This finding can be interpreted as that teams specify the set games they would use as a result of the analyses they carry out and try to perform the defense plans that can prevent them. This issue is also presented as a noticeable change in the report on the 2016 World Cup developed by FIFA (FIFA, 2016). Since there is no other study conducted in this respect in the related literature, failing to make a comparative evaluation is the limitation of our study.

In winning a game, producing shot positions and their accuracy levels are other important factors affecting success. In our study, significant differences were found between winning and losing particularly in the number of shots and shots on target. In the study carried out by Göral and Saygin in 2011, similar results were obtained indicating that shot numbers of the winning teams and shot accuracy ratios at these positions were higher. These findings reveal that winning teams can create positions that allow players with or without ball to take more shots. In this respect, it could be asserted that focusing on mobile offensive variations (transitions, parallel game, diagonal game, pivot game, screening etc) in the design of trainings would allow for creating more space. Producing these positions may help increase the number of shots and their accuracy levels. However, another point to be remembered here is the physical qualities and the shot techniques they have, which means the selection of players who have talent for futsal will be an important factor. In selecting futsal players, it can be said that choosing players who have high capability of mobility, can produce space for himself/herself within the game and can combine these qualities with (successful) shots could be an effective factor is the success of teams even at the starting stage.

In the examination of the zones where shots on goal were taken and their ending points in the goal, important findings were obtained concerning both goalkeepers and players. It was found that kicks taken from the front of the penalty area $\left(4^{\text {th }}-5^{\text {th }}-6^{\text {th }}\right.$ zones $)$ were towards to side and lower part of the goal pole at a distance from the kicking point to the $4^{\text {th }}$ and $6^{\text {th }}$ zones of the goal. The use of these zones made up of $74 \%$ of the total goals scored. In kicks from inside the penalty area and the sides close to the goal, it is seen that offense players prefer the central zone $\left(5^{\text {th }}\right.$ zone) of the goal $(52 \%$ successful shots). In line with these data, in the shooting practices to be performed, designing target oriented practices can contribute significantly for teams to achieve good results. Additionally, looking from the opposite direction, in training practices of goalkeepers and defense players, performing position taking practices that can close the angles of these zones according to the kicking points can be beneficial in reducing the number of conceded goals. It would make a big difference in the teams' chance of winning in both situations.

In the analysis of the distribution of the winning teams' goals by time (1-10, 11-20, 21-30, 31-40 minutes) during the tournament, the winning teams were observed to have been more successful particularly in comparison with the losing teams in terms of all time distributions. Considering that generally more goals are scored in the second parts of both halves in such tournaments, it can be said that this result does not affect winning teams. It could also be stated that winning teams complete all games with a disciplined understanding of game eliminating the effect of fatigue that occurs during the game.

\section{References}

Alvarez, J. C. B., D'Ottavio, S., Vera, J. G., \& Castagna, C. (2009). Aerobic fitness in futsal players of different competitive level. The Journal of Strength \& Conditioning Research,23(7), 2163-2166. https://doi.org/10.1519/JSC.0b013e3181b7f8ad

Alvurdu, S. (2013). UEFA Futsal Euro 2012: Türkiye Futsal Milli Takimi'nin grup maçlari teknik ve taktik analizi. Pamukkale Journal of Sport Sciences, 4(4), 105-111.

Ayala, F., De Baranda, P. S., Croix, M. D. S., \& Santonja, F. (2012). Absolute reliability of five clinical tests for assessing hamstring flexibility in professional futsal players. Journal of Science and Medicine in Sport, 15(2), 142-147. https://doi.org/10.1016/j.jsams.2011.10.002

Balyan, M., Vural, F., \& Katipoğlu, M. (2016). Salon Futbolu, İzmir,Turkiye, Ege Üniversitesi Basımevi

Bangsbo, J., \& Peitersen, B. (2000). Soccer Systems and Strategies. Human Kinetics, Champaign, IL

Barbero-Alvarez, J. C., Soto, V. M., Barbero-Alvarez, V., \& Granda-Vera, J. (2008). Match analysis and heart rate of futsal players during competition. Journal of Sports Sciences, 26(1), 63-73.

https://doi.org/10.1080/02640410701287289

Bueno, M., Caetano, F. G., Souza, N. M., Moreira G. D., Nakamura, F.Y., Cunha, S. A., \& Moura, F. A. (2014). Analysis of the distance covered by Brazilian professional futsal players during official matches, Sport Biomechanics, 13(3), 230-240. https://doi.org/10.1080/14763141.2014.958872

Burns, T. (2003). Holistic Futsal: a total mind-body-spirit approach, New York, NY:Lulu Press 
Castagna, C., \& Alvarez, J. C. B. (2010). Physiological demands of an intermittent futsal-oriented high-intensity test. The Journal of Strength \& Conditioning Research, 24(9), 2322-2329. https://doi.org/10.1519/JSC.0b013e3181e347b9

Castagna, C., D’Ottavio, S., Vera, J. G., \& Álvarez, J. C. B. (2009). Match demands of professional Futsal: a case study. Journal of Science and Medicine in Sport, 12(4), 490-494. https://doi.org/10.1016/j.jsams.2008.02.001

Costa, I., Garganta, J., Greco, P., Mesquita, I., Silva, B., Müller, E., \& Seabra, A. (2010). Analysis of tactical behaviours in small-sided soccer games: Comparative study between goalposts of society soccer and futsal. Open Sports Sciences Journal, 3, 10-12. https://doi.org/10.2174/1875399X01003010010

Dogramaci, S. N., Watsford, M. L., \& Murphy, A. J. (2011). Time-motion analysis of international and national level futsal. The Journal of Strength \& Conditioning Research, 25(3), 646-651. https://doi.org/10.1519/JSC.0b013e3181c6a02e

Dos Santos, M. A. B., \& Navarro, A. C. (2010). Analysis of the goals of Fifa World Cup of Futsal in 2008/Analise dos gols da Copa do Mundo de Futsal Fifa 2008. Revista Brasileira de Futsal e Futebol, 2(4), 33-37.

FIFA (2012). FIFA Futsal World Cup-Technical report and statistics

FIFA (2016). FIFA Futsal World Cup-Technical report and statistics

FIFA Eğitim Yayını. (2012). Training for Futsal Coaches. Türkiye Futbol Federasyonu (Çev.). "Çocuk ve Gençler için Futsal Çalı̧smaları. İstanbul: TFF Eğitim Yayınları.

Göktepe, M. (2014). Futsalda Taktik-Strateji Belirleme Yöntemleri, Ankara, Spor Yayınevi ve Kitabevi.

Göral, K., \& Saygın, Ö. (2011). 2012 FIFA Futsal Dünya Kupasının Analizi. CBÜ Beden Eğitimi ve Spor Bilimleri Dergisi, 6(1), 28-35.

Hermans, V., \& Engler, R. (2010). Futsal: Technique, tactics, training. Meyer \& Meyer Verlag.

Lapresa, D., Álvarez, L., Arana, J., Garzón, B., \& Caballero, V. (2013). Observational analysis of the offensive sequences that ended in a shot by the winning team of the 2010 UEFA Futsal Championship. Journal of Sports Sciences, 31(15), 1731-1739. https://doi.org/10.1080/02640414.2013.803584

Leite, W. S. S. (2012). Analysis of the offensive process of the Portuguese futsal team: A comparison between the actions of finalization. Pamukkale Journal of Sport Sciences, 3(3), 78-89.

Martic M., "FIFA Futsal Coaching Course" Antalya, 19-23.12.2016

Moura, F. A., Santana, J. E., Marche, A. L., Aguiar, T. H., Rodrigues, A. C. M., de Barros, R. M., \& Cunha, S. A. (2011). Quantitative analysis of futsal players' organization on the court. In ISBS-Conference Proceedings Archive, 1(1).

Ocak, Y., \& Buğdaycı, Ș. (2011) Futsal, İstanbul: Bedray Yayınları

Ren, D. M. (2013). Research on the Passing Characteristics of Futsal Game. Journal of Beijing University of Physical Education, 36(1), 123-126.

Silva, M., Costa, F., Souza, P., \& Greco, P. (2004). Ações ofensivas no futsal: uma comparação entre as situações de jogo organizado, de contra-ataque e de bola parada. Revista Portuguesa de Ciências do Desporto, Porto, 4(2), 199.

Travassos, B., Araújo, D., Davids, K., Esteves, P. T., \& Fernandes, O. (2012). Improving passing actions in team sports by developing interpersonal interactions between players. International Journal of Sports Science \& Coaching, 7(4), 677-688. https://doi.org/10.1260/1747-9541.7.4.677

Travassos, B., Duarte, R., Vilar, L., Davids, K., \& Araújo, D. (2012). Practice task design in team sports: Representativeness enhanced by increasing opportunities for action. Journal of Sports Sciences, 30(13), 1447-1454. https://doi.org/10.1080/02640414.2012.712716

Vilar, L., Araújo, D., Davids, K., Travassos, B., Duarte, R., \& Parreira, J. (2014). Interpersonal coordination tendencies supporting the creation/prevention of goal scoring opportunities in futsal. European Journal of Sport Science, 14(1), 28-35. https://doi.org/10.1080/17461391.2012.725103

\section{Copyrights}

Copyright for this article is retained by the author(s), with first publication rights granted to the journal.

This is an open-access article distributed under the terms and conditions of the Creative Commons Attribution license which permits unrestricted use, distribution, and reproduction in any medium, provided the original work is properly cited. 